\title{
Comparison of Serum Level of Vitamin D3 in Covid-19 Patients and Non-Infected Individuals
}

\author{
Alireza Nikoonejad $^{\text {(iD) }}$, Ali Shafizadeh Arjomandi², Samira Dodangeh ${ }^{3}$, Abbas Allami ${ }^{4, *}$ (iD) \\ ${ }^{1}$ Assistant Professor, Department of Infectious Diseases, Clinical Research Development Unit, BouAli Sina Hospital, Qazvin \\ University of Medical of Sciences, Qazvin, Iran \\ ${ }^{2}$ General Practitioner, Clinical Research Development Unit, BouAli Sina Hospital, Qazvin University of Medical of Sciences, \\ Qazvin, Iran \\ 3 PhD, Department of Medical Parasitology and Mycology, Medical Microbiology Research Center, Children Growth \\ Research Center, Research Institute for Prevention of Non-Communicable Diseases, Qazvin University of Medical Sciences, \\ Qazvin, Iran \\ ${ }^{4}$ Professor, Department of Infectious Diseases, Clinical Research Development Unit, BouAli Sina Hospital, Qazvin University \\ of Medical Sciences, Qazvin, Iran
}

* Corresponding Author: Abbas Allami, Department of Infectious Diseases, Clinical Research Development Unit, BouAli Sina Hospital, Qazvin University of Medical Sciences, Qazvin, Iran. Email: allami9@yahoo.com

Received: 06.12.2020

Accepted: 13.04 .2021

How to Cite this Article: Nikoonejad A, Shafizadeh Arjomandi A, Dodangeh S Allami A. Comparison of Serum Level of Vitamin D3 in Covid19 Patients and Non-Infected Individuals. Avicenna $J$ Clin Med. 2021; 28(1): 13-19. DOI: 10.52547/ajcm.28.1.13

\section{Abstract}

Background and Objective: Coronavirus Disease 2019 (COVID-19) has caused the death of many people, mainly by causing respiratory failure. The method of quarantine for the control of this disease leads to deprivation of vitamin D3 production. In this regard, this study aimed to investigate the relationship between serum vitamin D3 level and risk of COVID-19.

Materials and Methods: This case-control study was conducted in BouAli Sina Hospital in Qazvin, Iran in September 2020. The statistical population of the case group included patients with COVID-19 referred to this center, while the control group comprised non-COVID-19 patients who referred to the center. Vitamin D3 levels of the participants were assessed and the findings were recorded. The collected data were analyzed using statistical tests.

Results: The case group with positive COVID-19 included 81 patients and the control group consisted of 77 patients. The mean age of the subjects was $44.80 \pm 14.40$ years, and 67 of them were male. Based on the findings, 66 (81.5\%) out of all the patients with COVID-19 were deficient in vitamin D3, while in the control group, 44 (57.1\%) subjects were deficient in vitamin D3 $(\mathrm{P}=0.001)$.

Conclusion: In this study, it was found that vitamin D3 is an acceptable protective factor against COVID-19 and its deficiency will increase the risk of developing this disease.

Keywords: COVID-19, Risk Factors, Vitamin D3 Deficiency 


\section{مقايسه سطح سر مى ويتامين D3 در بيماران آلوده به ويروس كوويد-19 با افراد}

\section{فير مبتلا}

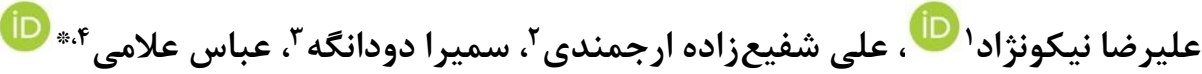

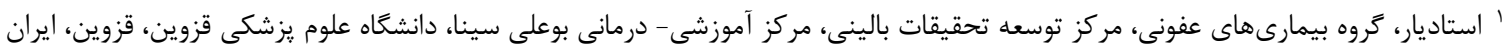

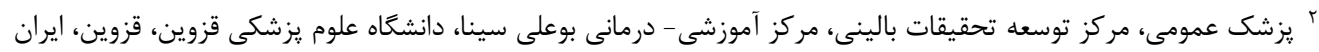

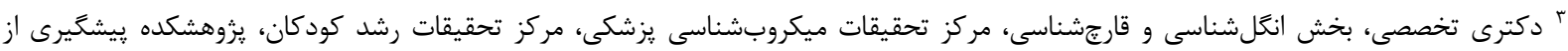

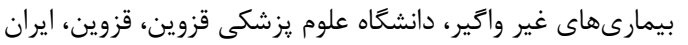

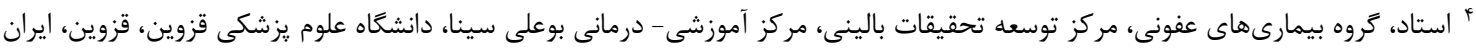
* نويسنده مسئول: عباس علامى، كروه بيمارىهاى عفونى، مركز توسعه تحقيقات بالينى، مركز آموزشى- درمانى بوعلى سينا، دانشكاه علوم يزشكى قزوين، قزوين، ايران. ايميل: allami9@yahoo.com

\begin{tabular}{|c|c|}
\hline جكيده & \\
\hline سابقه و هدف: كروناويروس 19 • Y (COVID-19: Coronavirus disease 2019) در اثر نارسايى تنفسى & 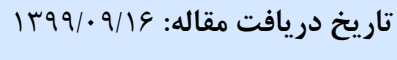 \\
\hline معمولاً باعث مرك بسيارى از افراد شده و به كاركيرى روش قرنطينه كردن موجب محروم شدن افراد از ساخت & 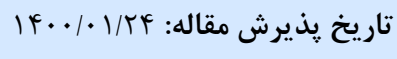 \\
\hline ويتامين D3 مى كردد. در اين راستا، مطالعه حاضر با هدف بررسى ارتباط وضعيت ويتامين D3 و ريسك ابتلا & تمامى حقوق نشر براى دانشكاه علوم \\
\hline مواد و روشها: مطالعه مورد- شاهدى حاضر در بيمار ستان "بوعلى سينا" قزوين طى شهريور ماه سال & 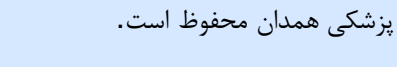 \\
\hline وج" ا انجام شد. كروه مورد، بيماران مبتلا به COVID-19 مراجعه كننده به اين مركز بودند. كروه شاهد نيز & \\
\hline از بين مراجعهكندكان غير مبتلا به COVID-19 انتخاب شدند. در اين مطالعه سطح سرمى ويتامين D3 & \\
\hline شركت كنند كان مورد بررسى قرار كرفت و نتايج ثبت كرديد. دادههاى به دست آمده با استفاده از آزمونهاى & \\
\hline 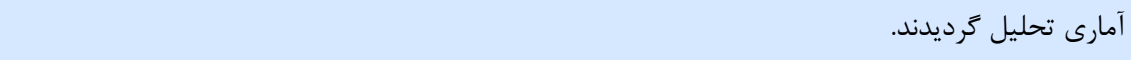 & \\
\hline يافته ها: كروه مورد كه نتيجه آزمايش COVID-19 آنها مثبت بود، 11 نفر و كروه شاهد، VV نفر بودند. & \\
\hline 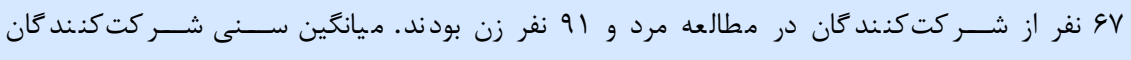 & \\
\hline 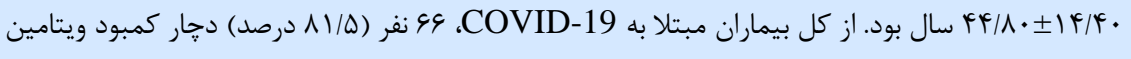 & \\
\hline 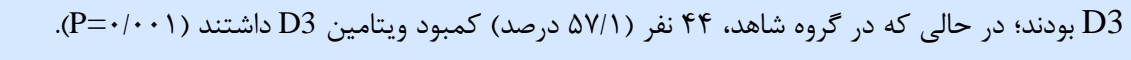 & \\
\hline نتيجهَيرى: نتايج نشـان دادند كه ويتامين D3 يك عامل حفاظتى قابل قبول در مقابل بيمارى COVID-19 & \\
\hline است و كمبود آن موجب افزايش احتمال ابتلا به اين بيمارى خواهد شد. & \\
\hline وازَّان كليدى: عوامل خطر، كروناويروس، كمبود ويتامين D3 & \\
\hline
\end{tabular}

شدهاند [ـ][. با اين وجود، مشاهدات اخير در مورد تأثير نسبتاً

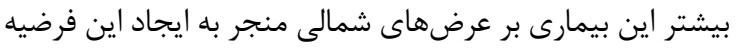

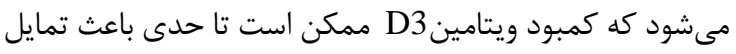

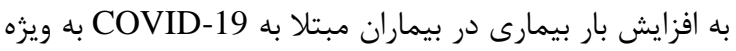

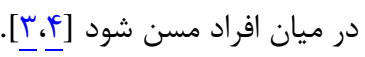

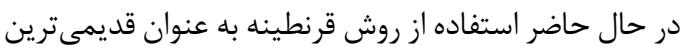

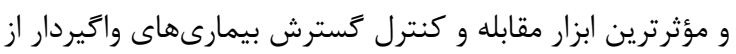

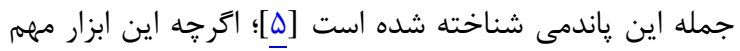

مقدمه

SARS-CoV-) بيمارى كروناويروس سندروم حاد تنفسى

(2: Severe acute respiratory syndrome coronavirus 2 كه در سال 9 أب با عنوان كروناويروس جديد (COVID-19)

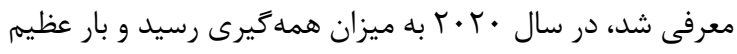

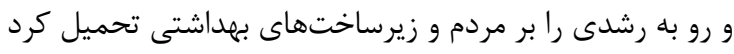

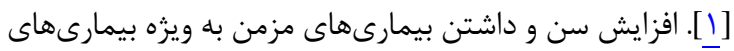

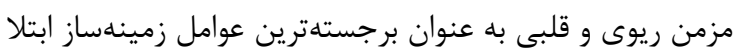
به COVID-19 فاز حاد و در نتيجه مركى و مير در نظر كرفته ندانه 
ذكر شده ماليده گَت و جند بار ترخانده شد. نمونهها در لوله

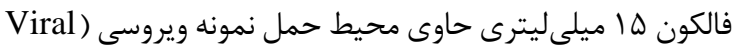

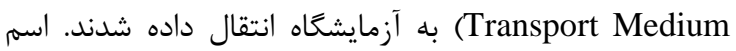
بيمار همراه با كد نمونه روى لوله درج گرديد. تمامى مراحل حمل

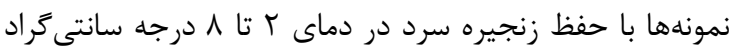

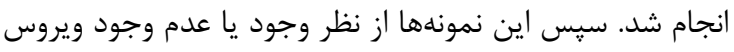
SARS-CoV-2

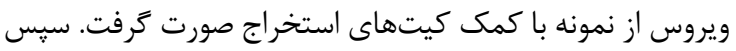

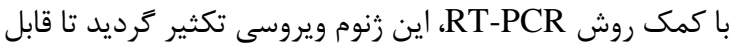
شناسايى شود. بايد خاطرنشان ساخت كه غالباً جواب آزمايش تردي

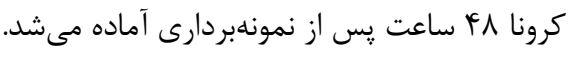

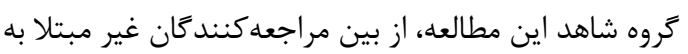

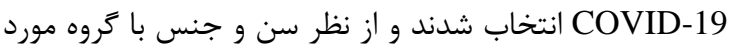
مطابقت داشتند. جامعه آمارى مطالعه، تمام بيمارانى را كه به هر أند دليل به كلينيك بيمارىهاى تنفسى مركز درمانى بوعلى سيناى

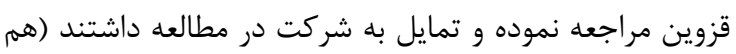

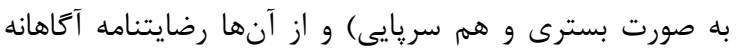

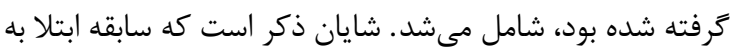

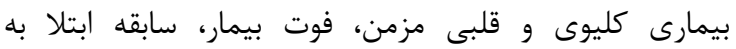

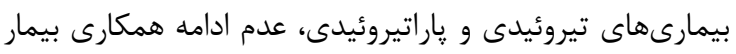

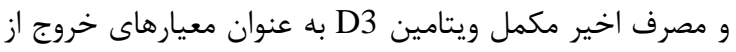

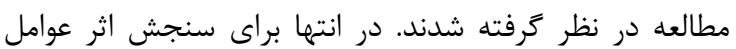

مخدوش

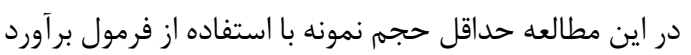

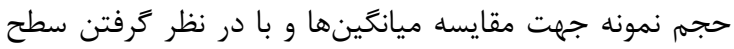

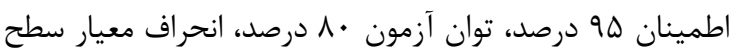

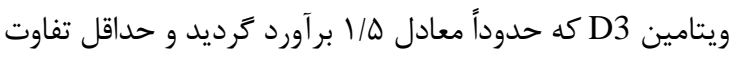
معنادار بين دو كروه مبتلا و غير مبتلا به

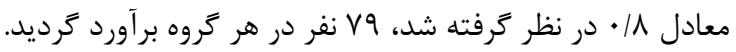

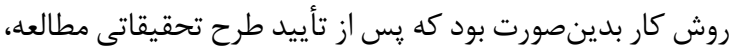

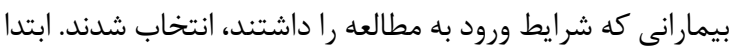
اطلاعات دموگر افيك اين افراد (سن، جنس ورو بط سطح تحصيلات)

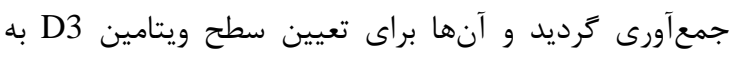

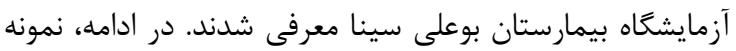

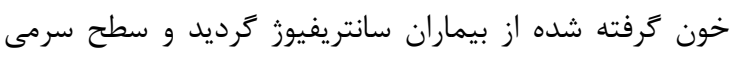

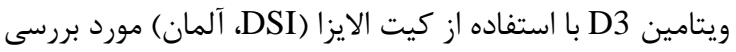

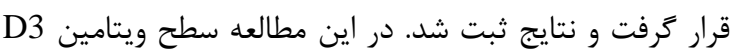

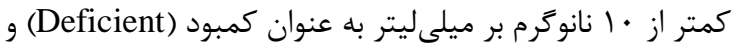

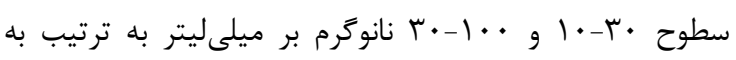

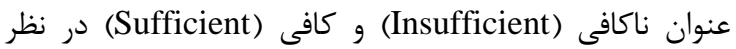
كرفته شدند. - منان

SPSS 25 دادهاى مطالعه يس از جمع آورى، وارد نرمافزار

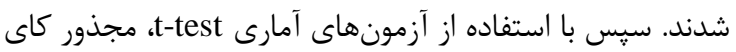

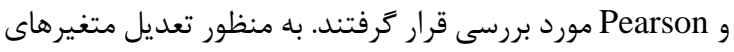

خود موجب كاهش و حتى عدم توليد ويتامين D3 در يوست

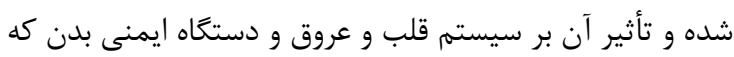

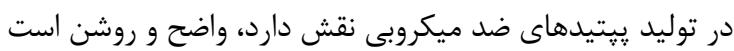

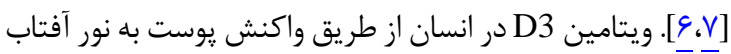

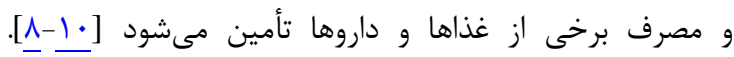

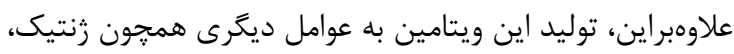

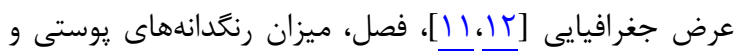

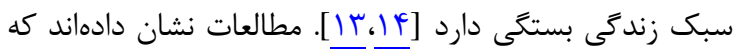

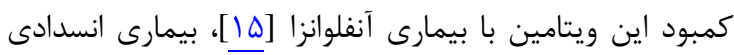

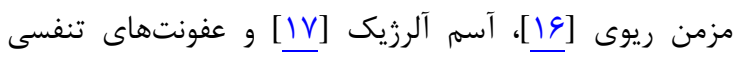
فوقانى همراه است [11]].

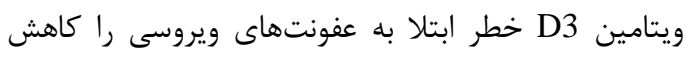
مى دهد و اثرات مطلوبى بر ريه و عملكرد سيستم ايمنى دارد إنى

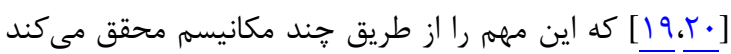

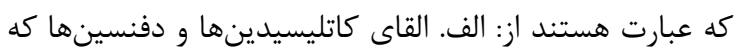

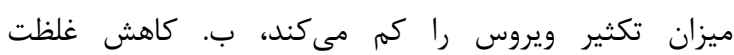

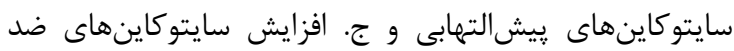

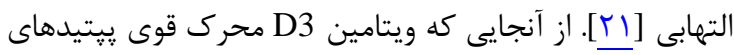

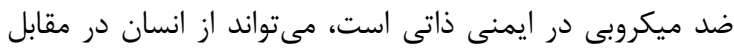

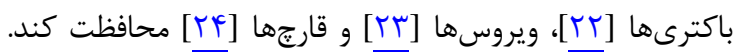

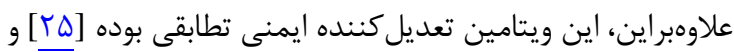
كزارش شده است كه مصرف مكمل اين ويتامين مى تواند حدوداً

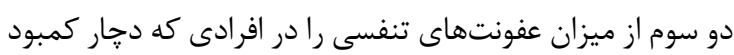

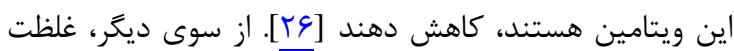

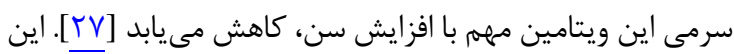

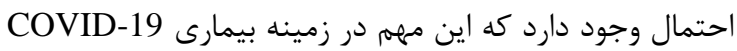

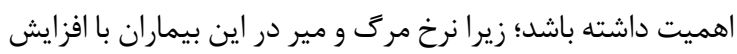
سن، بيشتر مىشود. با توجه به اهميت موارد ذكر شده، مطالعه حاضر با هدف بند

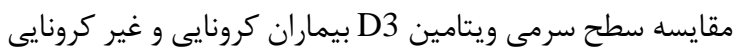
مراجعه كننده به بيمارستان بوعلى سيناى قزوين انجام شد.

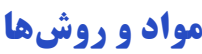

مطالعه مورد- شاهدى حاضر به شيوه سرشمارى در شهريور

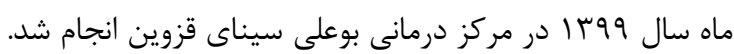
جامعه آمارى مورد مطالعه، بيماران مبتلا به

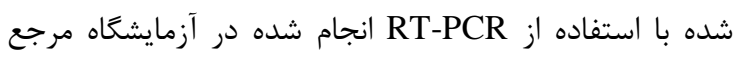

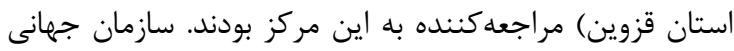

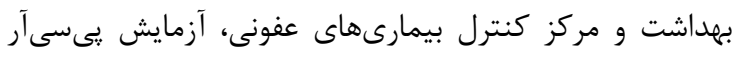
RT-PCR: Reverse transcription polymerase chain ) l, (reaction

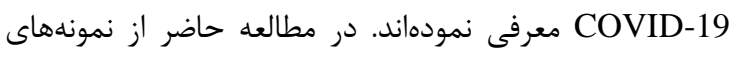

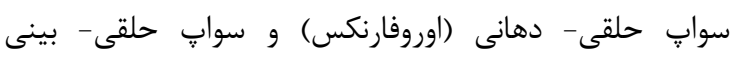

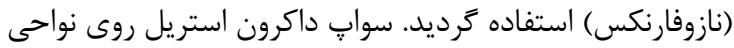


ميان 49 بيمار دجار كمبود ويتامين D3، ه ه نفر در سطح ناكافى

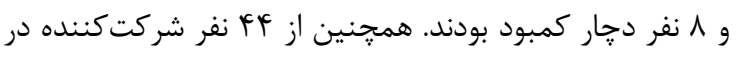

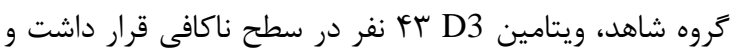

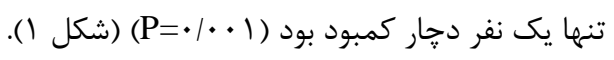

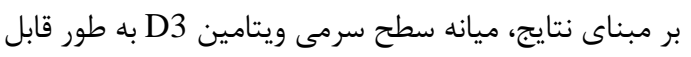

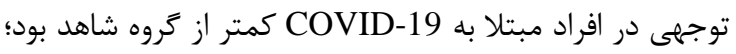
م

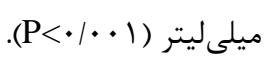
براساس نتايج آزمون رگرسيون لجستيكى كه در آن بيامد

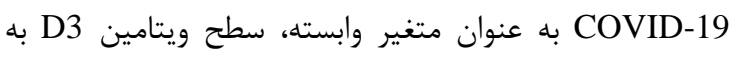
عنوان متغير يیشكويى كننده و وضعيت جنس، سطح تحصيلات و سن به عنوان متغيرهاى كوواريت تحليل گرديدند، مىتوان كفت كه با وجود حذف متغيرهاى بالقوه مخدوش كننده سطح

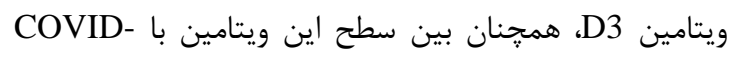
19ارتباط معنادارى وجود دارد و كمبود اين ويتامين، ريسك ابتلا

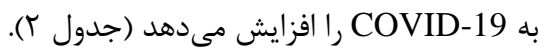

مداخلهَ از تحليل ركرسيون لجستيك استفاده زَرديد. نيز به عنوان سطح معنادارى در نظر كرفته شد.

بافْته ها

حروه مورد كه جواب RT-PCR آنها در ارتباط با ابتلا به

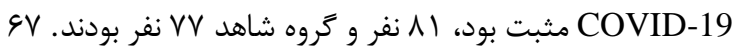
نفر از شركت كنند

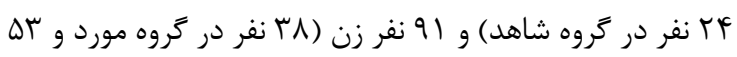

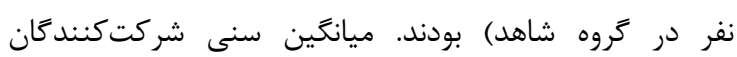
FF/A. I F/F.

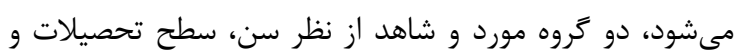

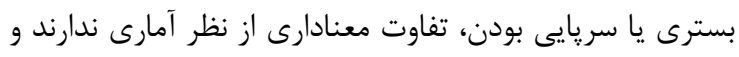
از اين نظر يكسان انتخاب شدهاند.

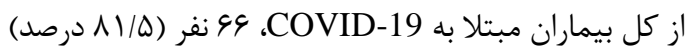
دجار كمبود ويتامين D3 بودند؛ در حالى كه در كروه شاهد،

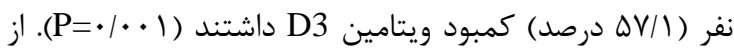

جدول ا: ويزّكى هاى دموَرافيك افراد مورد مطالعه

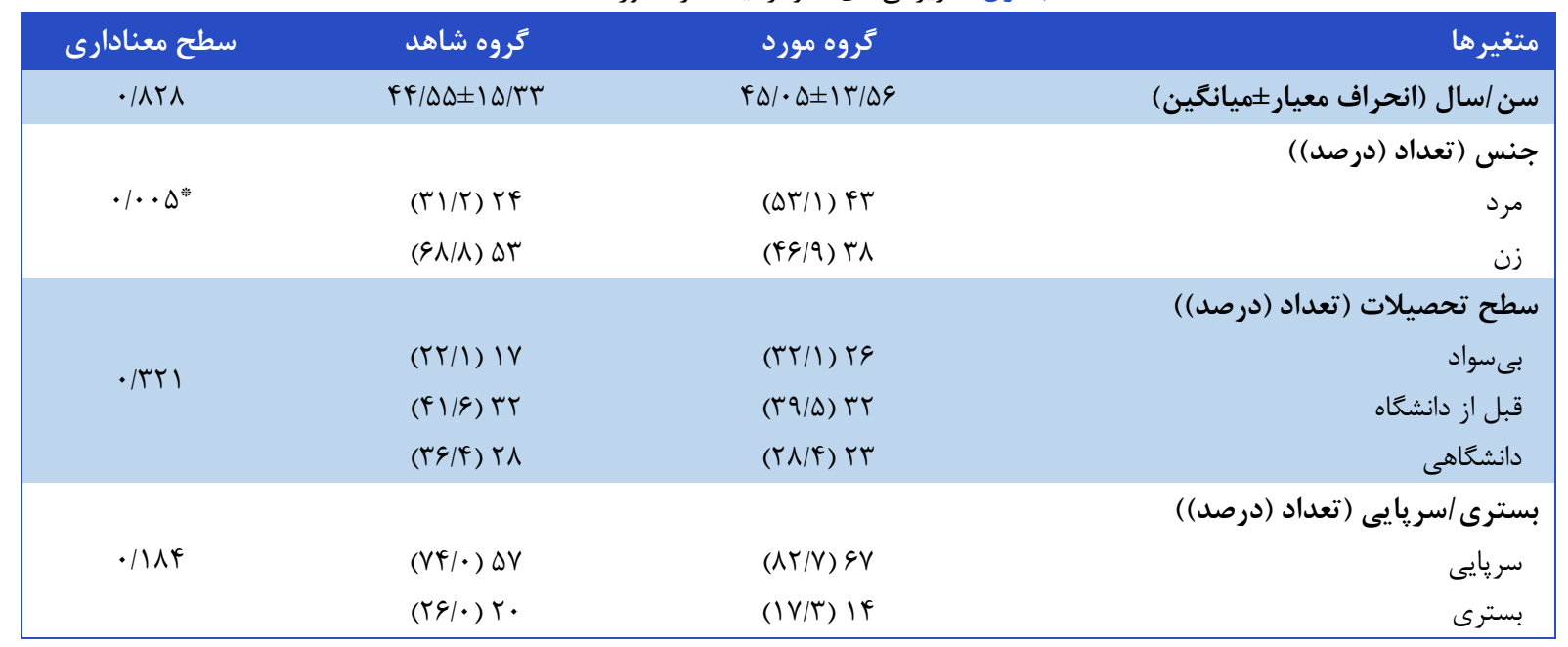

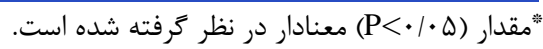

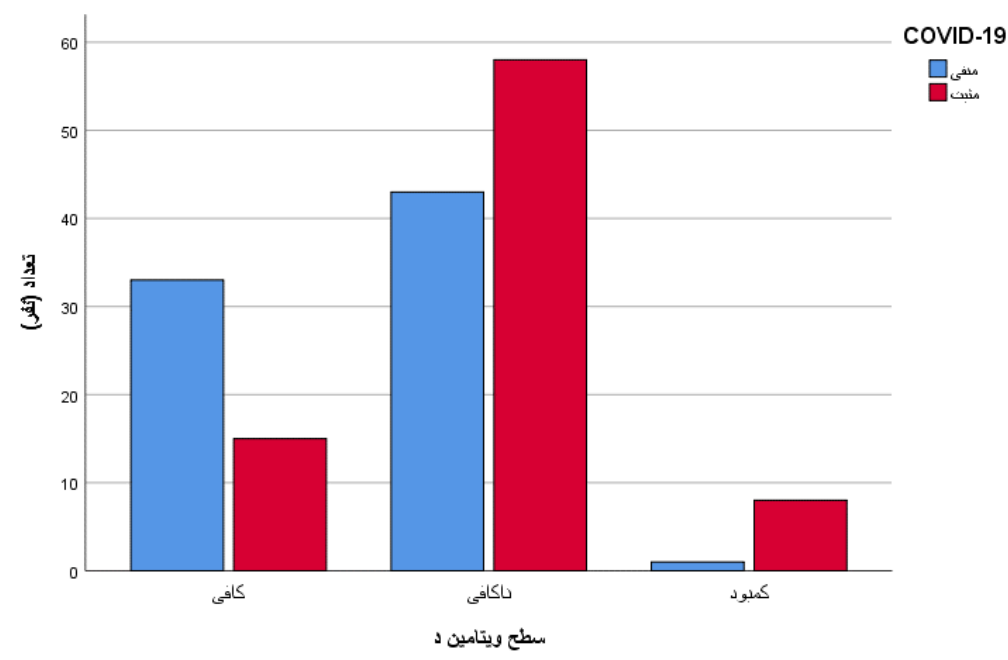

شكل ا: مقايسه سطوح ويتامين D3 در افراد مبتلا به COVID-19 و كروه شاهد 
جدول ب: نتايج برآورد نسبت شانس متغيرها در مدل ركرسيون

\begin{tabular}{|c|c|c|c|c|c|c|}
\hline 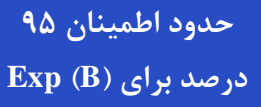 & نسبت شانس & معنادارى سطح & Wald & استاندارد & ضريب B & متغير \\
\hline $1 / T F T-\Delta / F / F$ & r/६9६ & $\cdot 1 \cdot \Delta$ & $V / V \Lambda$. & - /rDS & .1997 & جنس (مبنا: زن) \\
\hline $1 / \cdot V \cdot-9 / V H r$ & T/GNF & $\cdot / \cdot r \Delta$ & F/FTs & $\cdot / 499$ &.$/ 91 \mathrm{~V}$ & بسترى بودن \\
\hline$\cdot / \cdot r_{-} \cdot / r F$. & $\cdot / \cdot T F$ & $\cdot 1 \cdot \cdot 1$ & 1.1 .91 & l/IVF & $-r / V r q$ & ويتامين D3 D3 طبيعى (مبنا: كمبود \\
\hline$\cdot / \cdot 9-\cdot / V T V$ & $\cdot 1 \cdot \vee 9$ & $\cdot / \cdot r \Delta$ & $\Delta / \cdot r q$ & $1 / 1 \pi$. & $-r / T \Delta F$ & 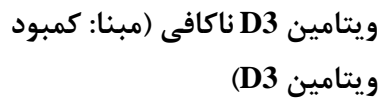 \\
\hline
\end{tabular}

Hosack ويتامين D3 موجب افزايش حضور ماركرهاى ييشكوى وقوع طوفان سايتو كينى و بيمارى شديد كمبود اين ماده حياتى را در شيوع و شدت اينى بيماري شديد بيمارى نشان

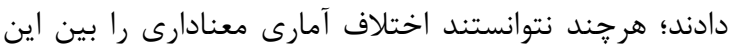

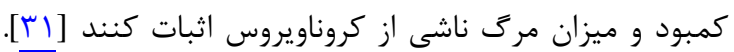
در اين راستا، Aygun در مطالعه خود بيان نمود كه ويتامين

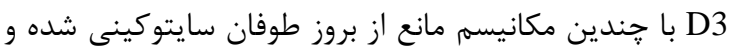

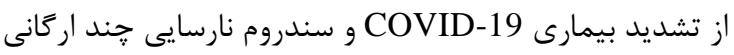
هيشگيرى (Multiple organ dysfunction syndrome)

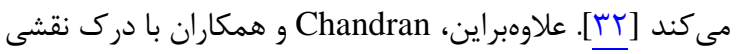

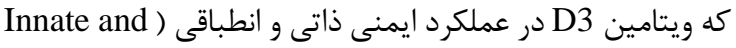

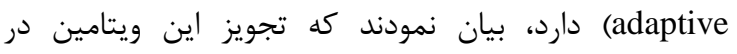
جلوگيرى از بروز طوفان سايتوكينى همجون آب بر آتش است

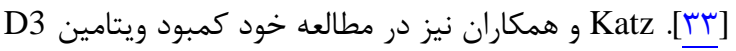
را از نظر تأثير بر شيوع و شدت بيمارى COVID-19 در كنار عوامل خطرى همجون نارسايى تنفسى و قلبى، ديابت، جاقى و

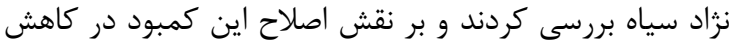

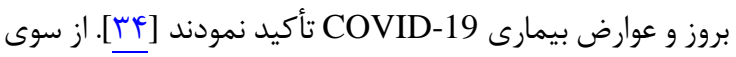

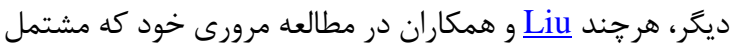

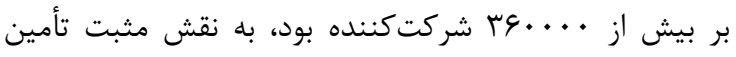

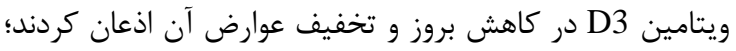
اما بيان نتيجه قطعى را به انجام مطالعات بيشتر موكول نمودند

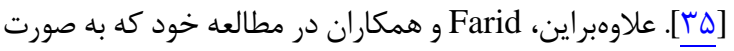

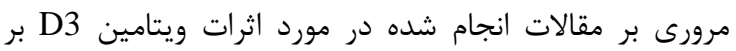

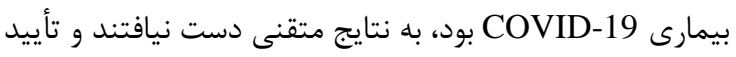

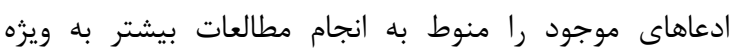

كلينيكال ترايالهاى وسيعتر دانستند [عبـ].

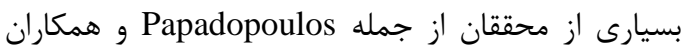
بيان نمودهاند كه شيوع بيمارى COVID-19 در مردان مسن،

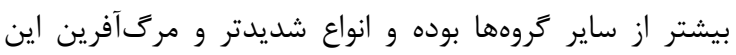

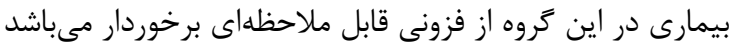

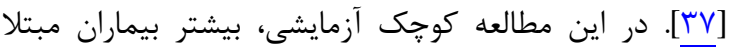

بر حسب نتايج مطالعه حاضر، بين ميانگين سنى دو گروه مبتلايان به COVID-19 و گروه شاهد تفاوت معنادارى مشاهده

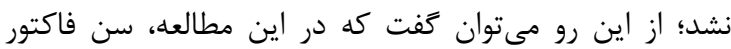
تأثير كذارى بر ابتلا به

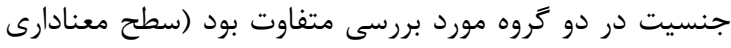

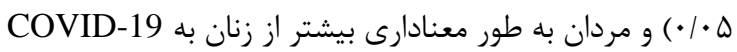

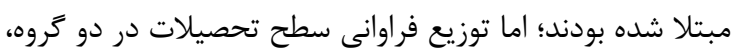

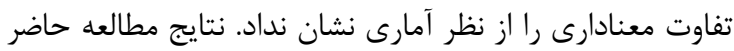

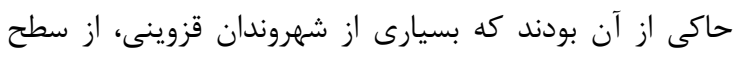
ناكافى ويتامين D3 كه نقش بسيار مهمى در در سلامت دستَّاه

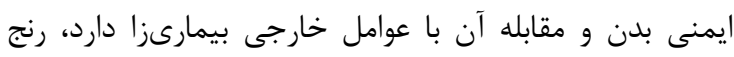

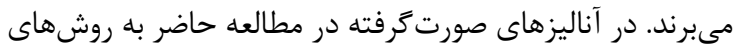
مختلف مشخص شد كه بيماران مبتلا به

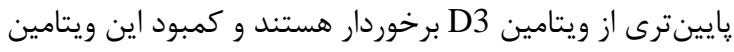
به شكل معنادارى با ابتلا به Kohlmeier

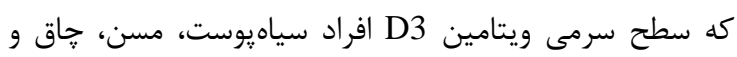

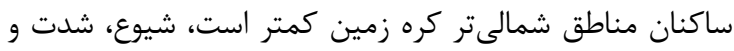

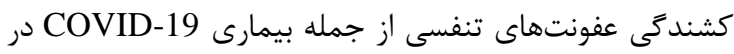

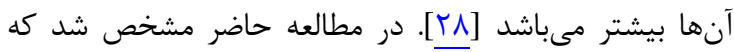

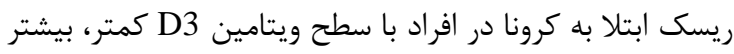

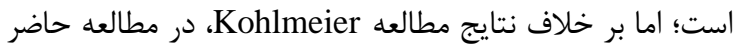

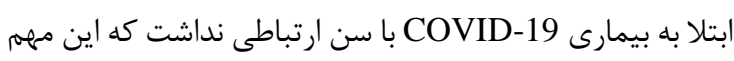

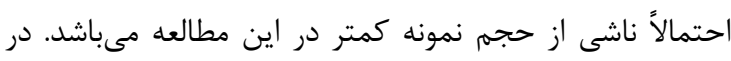

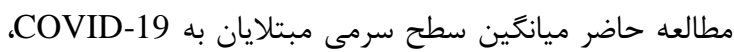

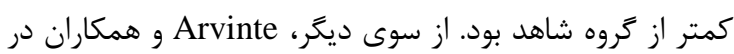

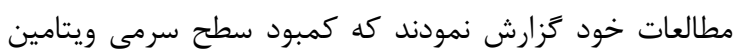

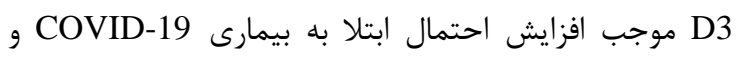

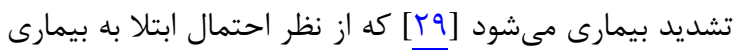
COVID-19 با نتايج مطالعه حاضر همسويى دارد. Luo و

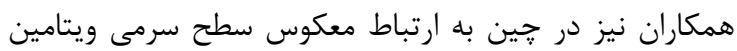

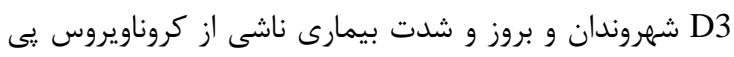
بردند [r] [ب]. 
آزمايشگاه بيمارستان بوعلى سيناى قزوين و تمام افرادى كه

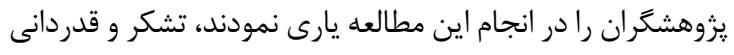

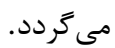

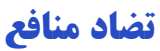
نويسند

\section{ملا حظات اخلاقى}

اين :روزه داراى تأييديه از كميته اخلاق دانشعاه علوم

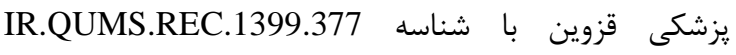

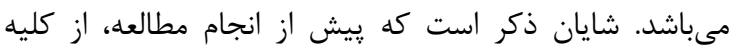
بيماران رضايتنامه آكاهانه دريافت شد.

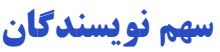

نويسنده اول (يزوهشكر اصلى): طراحى يروزه، تدوين بخش

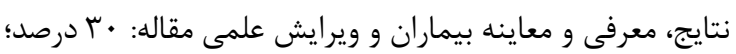

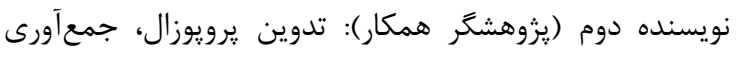

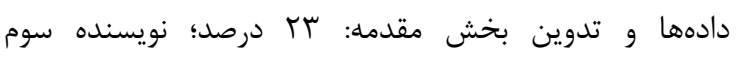

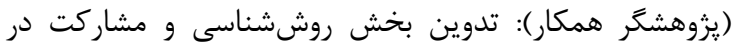

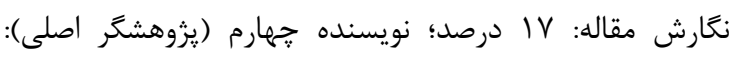
مسئول مكاتبات، مشاركت در طراحى يروزه، معرفى و معاينه

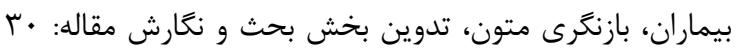
درصد

\section{حمايت مالى}

طرح حاضر از سوى معاونت تحقيقات و فناورى دانشعاه علوم

$$
\text { يزشكى قزوين تأمين مالى شده است. }
$$

\section{REFERENCES}

1. $\mathrm{Wu} \mathrm{Z,} \mathrm{McGoogan} \mathrm{JM.} \mathrm{Characteristics} \mathrm{of} \mathrm{and} \mathrm{important}$ lessons from the coronavirus disease 2019 (COVID-19) outbreak in China: summary of a report of 72314 cases from the Chinese Center for Disease Control and Prevention. JAMA. 2020;323(13):1239-42. PMID: 32091533 DOI: 10.1001/jama.2020.2648

2. Guan WJ, Liang WH, Zhao Y, Liang HR, Chen ZS, Li YM, et al. Comorbidity and its impact on 1590 patients with Covid-19 in China: a nationwide analysis. Eur Respir J. 2020;55(5):2000547. PMID: 32217650 DOI: 10.1183/13993003.00547-2020

3. Ilie PC, Stefanescu S, Smith L. The role of vitamin D in the prevention of coronavirus disease 2019 infection and mortality. Aging Clin Exp Res. 2020;32(7):1195-8. PMID: 32377965 DOI: $10.1007 / \mathrm{s} 40520-020-01570-8$

4. Kara M, Ekiz T, Ricci V, Kara Ö, Chang KV, Özçakar L. 'Scientific Strabismus' or two related pandemics: COVID-19 \& vitamin D deficiency. Br J Nutr. 2020;124(7):736-41 PMID: 32393401 DOI: 10.1017/S0007114520001749

5. Wilder-Smith A, Freedman DO. Isolation, quarantine, social distancing and community containment: pivotal role for oldstyle public health measures in the novel coronavirus (2019nCoV) outbreak. J Travel Med. 2020;27(2):taaa020. PMID: 32052841 DOI: $10.1093 /$ jtm/taaa020

6. Gröber U, Spitz J, Reichrath J, Kisters K, Holick MF. Vitamin D: update 2013: from rickets prophylaxis to general
به COVID-19، سطح سرمى ويتامين D3 كمى داشتند.

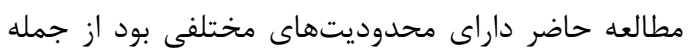

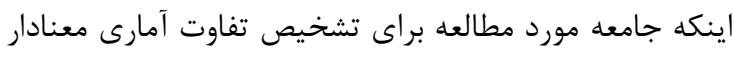

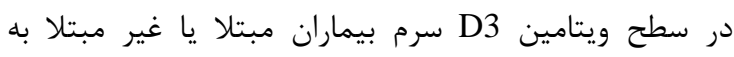

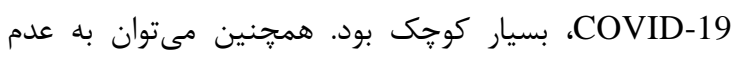

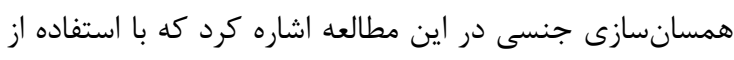

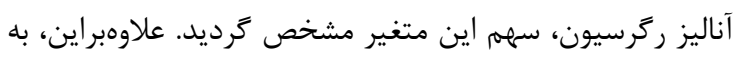

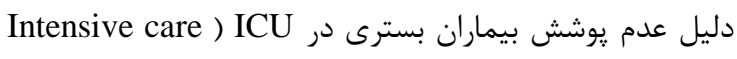

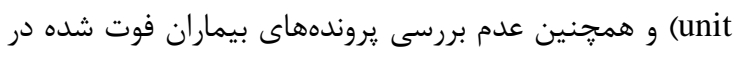

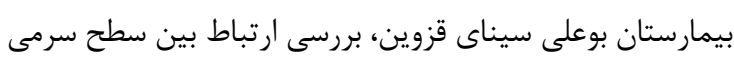

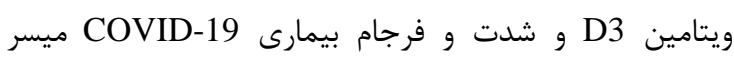
نكرديد. در انتها، پيشنههادات زير ارائه مى

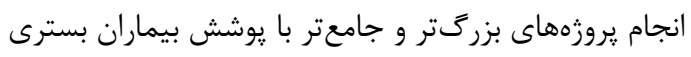

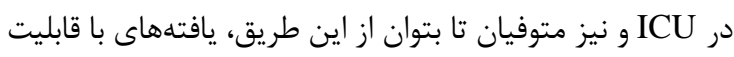

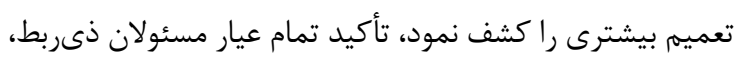
ساخت برنامههاى تلويزيونى مناسب و استفاده بهينه از فضاهاى

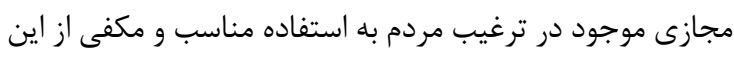
ماده مههم و حياتى در رزيم غذايى خود.

\section{نتيجه تيرى}

نتايج مطالعه حاضر نشان دادند كه كمبود ويتامين D3 (كه

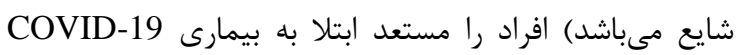
مى كند.

\author{
تشكر و قلروفاذى \\ اين مقاله بركرفته از يايان نامه دوره يزشكى عمومى مصوب

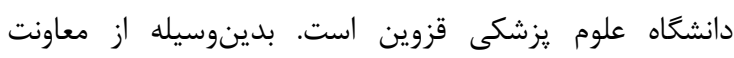

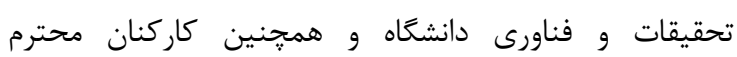

preventive healthcare. Dermatoendocrinol. 2013;5(3):33147. PMID: 24516687 DOI: $10.4161 /$ derm. 26738

7. Gunville CF, Mourani PM, Ginde AA. The role of vitamin D in prevention and treatment of infection. Inflamm Allergy Drug Targets. 2013;12(4):239-45. PMID: 23782205 DOI: 10.2174/18715281113129990046

8. Cannell JJ, Hollis BW. Use of vitamin D in clinical practice. Altern Med Rev. 2008;13(1):6-20. PMID: 18377099

9. Institute of Medicine (US) Standing Committee on the Scientific Evaluation of Dietary Reference Intakes. Dietary reference intakes. Dietary Reference Intakes for Calcium, Phosphorus, Magnesium, Vitamin D, and Fluoride. Washington, D.C: National Academies Press (US); 1997.

10. Jones G. Extrarenal vitamin D activation and interactions between vitamin D2, vitamin D3, and vitamin D analogs. Annu Rev Nutr. 2013;33:23-44. PMID: 23642201 DOI: 10.1146/annurev-nutr-071812-161203

11. Palacios C, Gonzalez L. Is vitamin D deficiency a major global public health problem? J Steroid Biochem Mol Biol. 2014;144(Pt A):138-45. PMID: 24239505 DOI: 10.1016/j.jsbmb.2013.11.003

12. Miller JW, Harvey DJ, Beckett LA, Green R, Farias ST, Reed BR, et al. Vitamin D status and rates of cognitive decline in a multiethnic cohort of older adults. JAMA Neurol. 2015;72(11):1295-303. PMID: 26366714 DOI: $\underline{10.1001 / \text { jamaneurol.2015.2115 }}$

13. Khazai N, Judd SE, Tangpricha V. Calcium and vitamin D: 
skeletal and extraskeletal health. Curr Rheumatol Rep. 2008;10(2):110-7. PMID: 18460265 DOI: $10.1007 /$ s11926008-0020-y

14. Wang TJ, Zhang F, Richards JB, Kestenbaum B, Van Meurs $\mathrm{JB}$, Berry D, et al. Common genetic determinants of vitamin D insufficiency: a genome-wide association study. Lancet. 2010;376(9736):180-8. PMID: 20541252 DOI: 10.1016/ S0140-6736(10)60588-0

15. Ross AC, Manson JE, Abrams SA, Aloia JF, Brannon PM, Clinton SK, et al. The 2011 report on dietary reference intakes for calcium and vitamin D from the Institute of Medicine: what clinicians need to know. J Clin Endocrinol Metab. 2011;96(1):53-8. PMID: 21118827 DOI: 10.1210/ jc. 2010-2704

16. Lee JY, So TY, Thackray J. A review on vitamin d deficiency treatment in pediatric patients. J Pediatr Pharmacol Ther. 2013;18(4):277-91. PMID: 24719588 DOI: $10.5863 / 1551-$ 6776-18.4.277

17. Dimeloe S, Nanzer A, Ryanna K, Hawrylowicz C. Regulatory $\mathrm{T}$ cells, inflammation and the allergic responsethe role of glucocorticoids and vitamin D. J Steroid Biochem Mol Biol. 2010;120(2-3):86-95. PMID: 20227496 DOI: 10.1016/j.jsbmb.2010.02.029

18. Lee MD, Lin CH, Lei WT, Chang HY, Lee HC, Yeung CY, et al. Does vitamin D deficiency affect the immunogenic responses to influenza vaccination? A systematic review and meta-analysis. Nutrients. 2018;10(4):409. PMID: 29587438 DOI: 10.3390/nu10040409

19. Zhang R, Naughton DP. Vitamin D in health and disease: current perspectives. Nutr J. 2010;9(1):65. PMID: 21143872 DOI: $10.1186 / 1475-2891-9-65$

20. Taylor CE, Camargo CA Jr. Impact of micronutrients on respiratory infections. Nutr Rev. 2011;69(5):259-69. PMID: 21521228 DOI: 10.1111/j.1753-4887.2011.00386.X

21. Grant WB, Lahore H, McDonnell SL, Baggerly CA, French $\mathrm{CB}$, Aliano JL, et al. Evidence that vitamin D supplementation could reduce risk of influenza and COVID19 infections and deaths. Nutrients. 2020;12(4):988. PMID: 32252338 DOI: $10.3390 /$ nu12040988

22. Komatsuzawa H, Ouhara K, Yamada S, Fujiwara T, Sayama $\mathrm{K}$, Hashimoto $\mathrm{K}$, et al. Innate defences against methicillinresistant Staphylococcus aureus (MRSA) infection. J Pathol. 2006;208(2):249-60. PMID: 16362993 DOI: 10.1002/path.1898

23. Klotman ME, Chang TL. Defensins in innate antiviral immunity. Nat Rev Immunol. 2006;6(6):447-56. PMID: 16724099 DOI: $10.1038 /$ nri1860

24. Schwalfenberg GK. A review of the critical role of vitamin D in the functioning of the immune system and the clinical implications of vitamin D deficiency. Mol Nutr Food Res. 2011; 55(1):96-108. PMID: 20824663 DOI: 10.1002/mnfr.201000174

25. Rondanelli M, Miccono A, Lamburghini S, Avanzato I, Riva A, Allegrini P, et al. Self-care for common colds: the pivotal role of vitamin D, vitamin C, zinc, and echinacea in three main immune interactive clusters (physical barriers, innate and adaptive immunity) involved during an episode of common colds - practical advice on dosages and on the time to take these nutrients/botanicals in order to prevent or treat common colds. Evid Based Complement Alternat Med. 2018; 2018:2813095. PMID: 29853961 DOI: 10.1155/2018/5813095

26. Bouillon R, Garmyn M, Verstuyf A, Segaert S, Casteels K, Mathieu C. Paracrine role for calcitriol in the immune system and skin creates new therapeutic possibilities for vitamin D analogs. Eur $J$ Endocrinol. 1995;133(1):7-16. PMID: 7627339 DOI: $10.1530 /$ eje. 0.1330007

27. Vásárhelyi B, Sátori A, Olajos F, Szabó A, Bekő G. Low vitamin D levels among patients at Semmelweis University: retrospective analysis during a one-year period. Orv Hetil. 2011;152(32):1272-7. PMID: 21803724 DOI: 10.1556/ OH.2011.29187

28. Kohlmeier M. Avoidance of vitamin D deficiency to slow the COVID-19 pandemic. BMJ Nutr Prev Health. 2020;3(1):6773. PMID: 33230496 DOI: 10.1136/bmjnph-2020-000096

29. Arvinte C, Singh M, Marik PE. Serum levels of vitamin C and vitamin $\mathrm{D}$ in a cohort of critically ill COVID-19 patients of a North American community hospital intensive care unit in May 2020: a pilot study. Med Drug Discov. 2020;8: 100064. PMID: 32964205 DOI: 10.1016/j.medidd.2020.100064

30. Luo X, Liao Q, Shen Y, Li H, Cheng L. Vitamin D deficiency is inversely associated with Covid-19 incidence and disease severity in Chinese people. J Nutr. 2021:151(3):742-3. PMID: 33704501 DOI: $10.1093 / \mathrm{jn} / \mathrm{n} \times a a 460$

31. Hosack T, Baktash V, Mandal AK, Missouris CG. Prognostic implications of vitamin D in patients with COVID-19. Eur J Nutr. 202;60(1):549-50. PMID: 33225401 DOI: 10.1007/s00394-020-02429-4

32. Aygun H. Vitamin D can prevent COVID-19 infectioninduced multiple organ damage. Naunyn Schmiedebergs Arch Pharmacol. 2020;393(7):1157-60. PMID: 32451597 DOI: $10.1007 / \mathrm{s} 00210-020-01911-4$

33. Chandran M, Maung AC, Mithal A, Parameswaran R. Vitamin D in COVID-19: dousing the fire or averting the storm?-A perspective from the Asia-Pacific. Osteoporos Sarcopenia. 2020;6(3):97-105. PMID: 32838048 DOI: 10.1016/j.afos.2020.07.003

34. Katz J, Yue S, Xue W. Increased risk for Covid-19 in patients with Vitamin D deficiency. Nutrition. 2021;84:111106. PMID: 33418230 DOI: 10.1016/j.nut.2020.111106

35. Liu N, Sun J, Wang X, Zhang T, Zhao M, Li H. Low vitamin D status is associated with coronavirus disease 2019 outcomes: A systematic review and meta-analysis. Int $J$ Infect Dis. 2021;104:58-64. PMID: 33401034 DOI: 10.1016/j.ijid.2020.12.077

36. Farid N, Rola N, Koch EA, Nakhoul N. Active vitamin D supplementation and COVID-19 infections. Ir J Med Sci. 2021;6:1-4. PMID: 33409846 DOI: 10.1007/s11845-020$\underline{02452-8}$

37. Papadopoulos V, Li L, Samplaski M. Why does COVID-19 kill more elderly men than women? Is there a role for testosterone? Andrology. 2021;9(1):65-72. PMID: 32681716 DOI: $10.1111 /$ andr.12868 